\title{
Prevalence and demographics of systemic lupus erythematosus and lupus nephritis among US children with Medicaid coverage, 2002-2004
}

\author{
Linda T Hiraki ${ }^{4 *}$, Tamara Shaykevich ${ }^{1}$, Wolfgang C Winkelmayer ${ }^{3}$, Karen H Costenbader ${ }^{2}$ \\ From 2011 Pediatric Rheumatology Symposium sponsored by the American College of Rheumatology \\ Miami, FL, USA. 2-5 June 2011
}

\section{Purpose}

Little is known about the prevalence or sociodemographics of systemic lupus erythematosus (SLE) among children on Medicaid, the government-funded program which pays for medical care for those who cannot afford it. We investigated nationwide prevalence and sociodemographic characteristics of SLE among children on Medicaid.

\section{Methods}

Children aged 5-19 years with SLE ( $\geq 2$ ICD-9 codes of 710.0) were identified from Medicaid Analytic eXtract (MAX) data, containing all inpatient and outpatient claims codes for Medicaid patients for all 50 U.S. States, 2002-2004. Within this group, lupus nephritis was identified from billing codes for $\geq 2$ of a range of ICD-9 codes for glomerulonephritis, proteinuria and renal failure (PPV $88 \%$, validated by Chibnik et al., 2009). We calculated the prevalence of SLE and lupus nephritis among Medicaid-eligible children and within specific sociodemographic segments.

\section{Results}

Of 25,531,034 children covered by Medicaid from 2002 to 2004,4515 with SLE were identified: SLE prevalence was 17.7 per 100,000 . Of those, $85 \%$ were female, $38 \%$ Black, 23\% Hispanic and 25\% White; $43 \%$ resided in the South and 23\% in the West. Overall, 1655 (37\%) of children with SLE had lupus nephritis (prevalence: 6.5 per 100,000). Table 1 shows the prevalence of SLE and lupus nephritis per 100,000 among specific demographic groups of children with Medicaid. Lupus nephritis was
Table 1 Prevalence of SLE and lupus nephritis among US children aged 5-19 years, 2002-2004, (per 100,000 Medicaid-eligible children)

\begin{tabular}{lll}
\hline & SLE & Lupus nephritis \\
\hline All ages 5-19 & 17.7 & 6.5 \\
Males & 5.5 & 2.1 \\
Females & 29.4 & 10.7 \\
Blacks & 24.6 & 10.1 \\
Whites & 10.4 & 2.8 \\
Asians & 31.4 & 13.1 \\
Hispanics & 20.0 & 7.0 \\
Native American & 28.5 & 12.9 \\
Northeast & 17.2 & 6.6 \\
South & 19.2 & 7.1 \\
Midwest & 14.2 & 4.8 \\
West & 18.6 & 6.7 \\
Age 5.9 & 2.7 & 0.9 \\
Age 10-14 & 17.7 & 6.5 \\
Age 15-19 & 49.5 & 18.3 \\
\hline
\end{tabular}

more common among Native American (45\%), Black (41\%), Asian (42\%) and Hispanic (35\%) children with SLE than among white children (27\%).

\section{Conclusion}

The prevalence of SLE among children with Medicaid medical insurance in the U.S., 2002-2004, was 17.7 per 100,000 . The majority was non-white and over a third had been evidence of lupus nephritis. Future studies are required to explore predictors of outcomes of SLE in this population.

${ }^{4}$ Harvard School of Public Health, Boston, MA, USA

Full list of author information is available at the end of the article

(c) 2012 Hiraki et al; licensee BioMed Central Ltd. This is an Open Access article distributed under the terms of the Creative Commons Attribution License (http://creativecommons.org/licenses/by/2.0), which permits unrestricted use, distribution, and reproduction in any medium, provided the original work is properly cited. 


\section{Disclosure}

Linda T. Hiraki: None; Tamara Shaykevich: None; Wolfgang C. Winkelmayer: None; Karen $\mathrm{H}$. Costenbader: None.

\section{Author details}

'Brigham and Women's Hospital, Boston, MA, USA. 'Brigham and Women's Hospital, Harvard School of Public Health, Boston, MA, USA. ${ }^{3}$ Department of Medicine, Stanford University School of Medicine, Palo Alto, CA, USA.

${ }^{4}$ Harvard School of Public Health, Boston, MA, USA.

Published: 13 July 2012

doi:10.1186/1546-0096-10-S1-A104

Cite this article as: Hiraki et al:: Prevalence and demographics of systemic lupus erythematosus and lupus nephritis among US children with Medicaid coverage, 2002-2004. Pediatric Rheumatology 201210 (Suppl 1):A104.

Submit your next manuscript to BioMed Central and take full advantage of:

- Convenient online submission

- Thorough peer review

- No space constraints or color figure charges

- Immediate publication on acceptance

- Inclusion in PubMed, CAS, Scopus and Google Scholar

- Research which is freely available for redistribution

Submit your manuscript at www.biomedcentral.com/submit 